\title{
Preparation and Characterization of Electrodeposited Aluminum Oxide Thin Films
}

\author{
Farzana Majid, Saira Riaz, Muhammad I. Akram, Shahid Atiq and Shahzad Naseem \\ Center of Excellence in Solid State Physics, University of the Punjab, Quaid-e-Azam Campus, Lahore-54590, Pakistan \\ saira_cssp@yahoo.com
}

\begin{abstract}
Aluminum Oxide $\left(\mathrm{Al}_{2} \mathrm{O}_{3}\right)$ deposition is being sought for application in space / aerospace as a barrier coating. $\mathrm{Al}_{2} \mathrm{O}_{3}$ not only changes the mechanical properties of the aluminum based alloys, it acts as a barrier for harmful radiations. Ionizing radiations are harmful to electronic components, which runaway due to extra charge carriers being produced, used in the space vehicles. We are employing electro-deposition along with sol-gel deposition in order to produce these coatings. Both of the techniques are simple, cheap and scalable. The prepared films are characterized by Scanning Electron Microscopy (SEM), Atomic Force Microscopy (AFM) and X-Ray Diffraction (XRD) for their structural / microstructural properties. In this paper, these properties are correlated to the deposition conditions in order to optimize the conditions for the applications mentioned above. The initial results being presented here are very encouraging regarding the smoothness of the films and the grain / particle size achieved so far.

Index Terms - Aluminum oxide, Electrodeposition, XRD, SEM, grain size
\end{abstract}

\section{I . Introduction}

Spacecraft, during their orbital life, experiences multiple and extreme environmental conditions. These environmental conditions may be due to natural factors (Vacuum, ionizing radiations, charge particle fluxes, micrometeoroids, atomic oxygen in low earth orbit) and artificial factors (space debris, contaminations, etc) ${ }^{1}$. These factors not only influence the mechanical, thermo optical properties for spacecraft but also its performance and life expectancy ${ }^{2}$. The biggest threat to spacecraft performance and life are the temperature anomalies during its orbital mission. Due to alternating passages of spacecraft in the earth shadow and in front of sun, a spacecraft experiences thermal cycling in the space vacuum ${ }^{3,4}$. This thermal cycling in spacecraft, orbiting the earth, produces thermal stresses inside the vehicle ${ }^{5}$ and causes temperature variations in the range of $-1400^{\circ} \mathrm{C}$ to $+1400^{\circ} \mathrm{C}^{6}$. In the space vacuum, the heat exchange between the spacecraft and its environment is through radiations ${ }^{7}$. The temperature maintenance of spacecraft is managed through radiative exchange between the earth, the moon, deep cold space, the sun and the external parts of spacecraft ${ }^{8}$. For optimum performance of spacecraft and to get fullest efficiency of its parts, the thermal system of the spacecraft must be designed carefully ${ }^{9}$.

Temperature conditions inside the spacecraft are maintained by protecting it from outer space extreme conditions e.g. charge particle bombardment through electrochemical coatings ${ }^{10}$. The electrochemical coatings act as protecting layers or balancing temperature layers that are used on spacecraft. Keeping in view, the importance and need of thermal coatings, there must be some criteria for choosing thermal coatings and for materials that are used as a substrate for such thermal coatings. Aerospace industry has in general boosted the interest for materials having high strength to weight ratio ${ }^{11}$. To get desired properties many researchers are doing efforts to design new alloys and to improve characteristics of existing alloys ${ }^{12}$. The $7 \mathrm{xxx}$ series (Al-Zn$\mathrm{Mg}-\mathrm{Cu}$ alloy) have exceptional properties like high strength to density ratio ${ }^{13}$, enhanced mechanical properties, high thermal and electrical conductivity, good resistance to oxidation and corrosion $^{14}$, improved wear resistance, high stiffness, low coefficient of thermal expansion ${ }^{15}$, recyclability and workability ${ }^{16}$. Due to these outstanding properties aluminum alloys are extensively used in development of aerospace structures ${ }^{17}$. Replacement and repair of structural components of spacecrafts have significant issues so aluminum 7075 has utmost importance ${ }^{13}$ to meet cost and weight requirements ${ }^{16}$. This high strength $\mathrm{Al}$ alloy has increased the life period of the structural parts of the space vehicles ${ }^{18}$. But aluminum alloys cannot be used directly in space because of severe operating conditions. Aluminum has pilling - Bedworth ratio ( $\mathrm{P}-\mathrm{B}$ ratio) $>1$, due to which protective oxide layer is formed in air that provides protection against further surface oxidation ${ }^{19}$.This oxide layer is heterogeneous ${ }^{20}$ and thin and its surface properties can be improved through electrochemical coatings 21

Good thermal coatings are the one which has low solar absorbance and high infrared emittance values ${ }^{7}$. The significance of infrared emittance is that, it controls the rate at which spacecraft emits radiations. The significance of solar absorbance for spacecraft is due to absorbed solar radiations that is the major external heat input to the spacecraft ${ }^{5}$. Research has shown that combined effect of above natural and artificial factors, responsible for temperature anomalies in thermal status of the spacecraft also produces degradation in optical properties of the coatings ${ }^{22,23}$. It causes solar absorptance factor to increase ${ }^{1}$ that can jeopardize flight worthiness of the spacecraft ${ }^{24}$. Therefore the role of optical properties is critical to maintain thermal control of the whole system and cannot be ignored for optimum performance of spacecraft ${ }^{25}$.

The severity of the impact of space environment on materials and coatings can be minimized by controlling the equilibrium temperature of the spacecraft by solar absorptance $\left(\alpha_{\mathrm{s}}\right)$ and infrared emittance $(\varepsilon)^{26-28}$. Anodization is an 
electrochemical conversion of the metal surface into metal oxide without addition of any external substances ${ }^{8}$. It is one of the most unique and frequently used methods to improve surface properties and anodized $\mathrm{Al}$ alloys have wide range of applications $^{29}$. By controlling the anodizing parameters (voltage, current density, time, electrolyte temperature and concentration etc) required properties of anodic films can be obtained $^{30}$. Different electrolytes are available for anodic layer formation but best structure is obtained in sulfuric acid ${ }^{29}$. The anodic coatings on aluminum alloys qualify to be used in aerospace applications due to their best properties such as better specular reflectivity ${ }^{31}$, low solar absorptance, high bonding strength with a substrate and durability in outer space environment ${ }^{28}$.

In this research work, deposition conditions of electrodeposited aluminum oxide thin films are optimized by varying voltage from $1-5$ volts at room temperature. Surface morphology is studied in detail by using SEM and AFM for their potential application as a barrier coatings.

\section{II . Experimental details}

All the reagents, used in this research work, were of analytical grade. Fresh neutral electrolytes were prepared, for all the depositions. The solution was de-aerated before each experiment. Electrodeposition was carried out in a threeelectrode cell with control of the temperature. Vertical arrangement of the working electrode was used for the growth of anodized aluminum oxide thin films. A microcomputercontrolled Versa stat 4 potentiostat/galvanostat was used for all the depositions.

Aluminum oxide thin films were characterized structurally by using Rigaku D/MAX-IIA X-ray Diffractometer $(\mathrm{CuK} \alpha=1.5405 \AA)$. Surface morphology was studied by using Hitachi S-3400N scanning electron microscope and Bruker CP-II atomic force microscope.

\section{Results and discussion}

Figure 1 shows XRD plots of electrodeposited aluminum oxide thin films. Presence of (222), (100) and (111) peak confirms the formation of $\mathrm{FCC} \mathrm{Al}_{2} \mathrm{O}_{3}$. Films are oriented preferentially along (222) plane. With increase in the potential form 3 to 5 volt the peak intensity corresponding to (222) plane increase confirming the preferred orientation of aluminum oxide films along (222) plane. XRD results of aluminum oxide films prepared at 1 and 2 volts are similar to the films prepared at 3 volts.

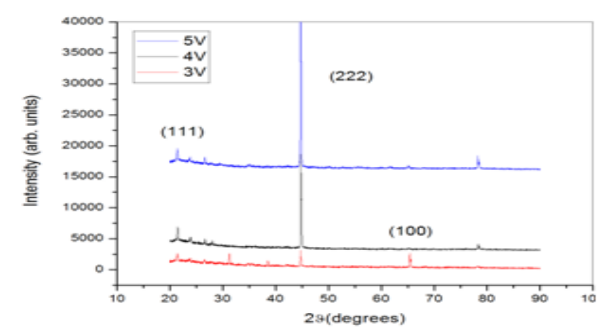

Fig. 1 XRD pattern for electrodeposited $\mathrm{Al}_{2} \mathrm{O}_{3}$ thin films
Figures 2(a-e) show SEM images of electrodeposited aluminum oxide thin films. Uniform dense microstructure is seen in these images. All the films are crack free and no pores are present in the films. Films comprised of elongated nanoparticles are observed at voltage of 1-3 volts [Figures $2 \mathrm{a}$ c]. However, reduction in the particle size, from $\sim 300 \mathrm{~nm}$ to $100 \mathrm{~nm}$, was observed by increasing the voltage. Diffused and agglomerated oxide nanostructure $(\sim 80 \mathrm{~nm})$ was observed by increasing the voltage from 3 to 4 volts, as shown in Figure $2 d$. Similar results were also observed on further increasing the voltage to 5 volts [Figure $2 \mathrm{e}$ ].
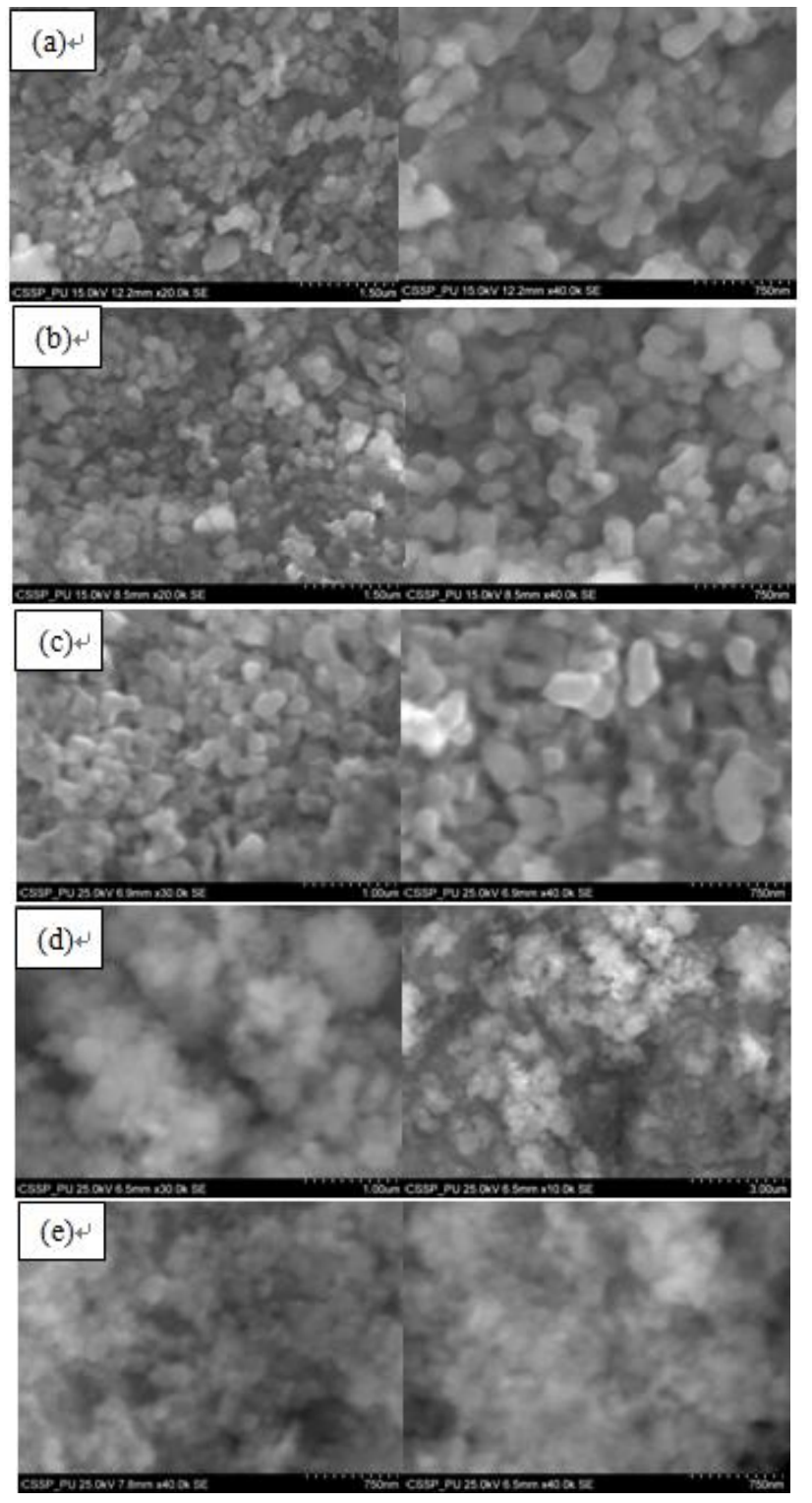

Fig. 2 SEM images of electrodeposited aluminum oxide thin films at (a) $1 \mathrm{~V}$, (b) $2 \mathrm{~V}$, (c) $3 \mathrm{~V}$, (d) $4 \mathrm{~V}$ and (e) $5 \mathrm{~V}$ for 15 minutes

It can be seen through SEM images in Figures 2(a-e) that change in surface morphology of aluminum oxide thin films is observed by increasing the voltage from 3 volts to onwards.

Riaz et $\mathrm{al}^{32}$ has shown that reaction time has also a 
significant effect on the formation of aluminum oxide thin films. More samples were prepared at $3 \mathrm{~V}$ for reaction time of 15mins, 30mins, 60mins and 90mins. SEM images [Figures $3(\mathrm{a}-\mathrm{c})$ ] show that by increasing the reaction time not only the shape is changed, elongated to spherical, but the nanoparticle size has also reduced. However, on further increasing the reaction time to 60 and 90 minutes, at 3 volts, discontinuity in the films increases.
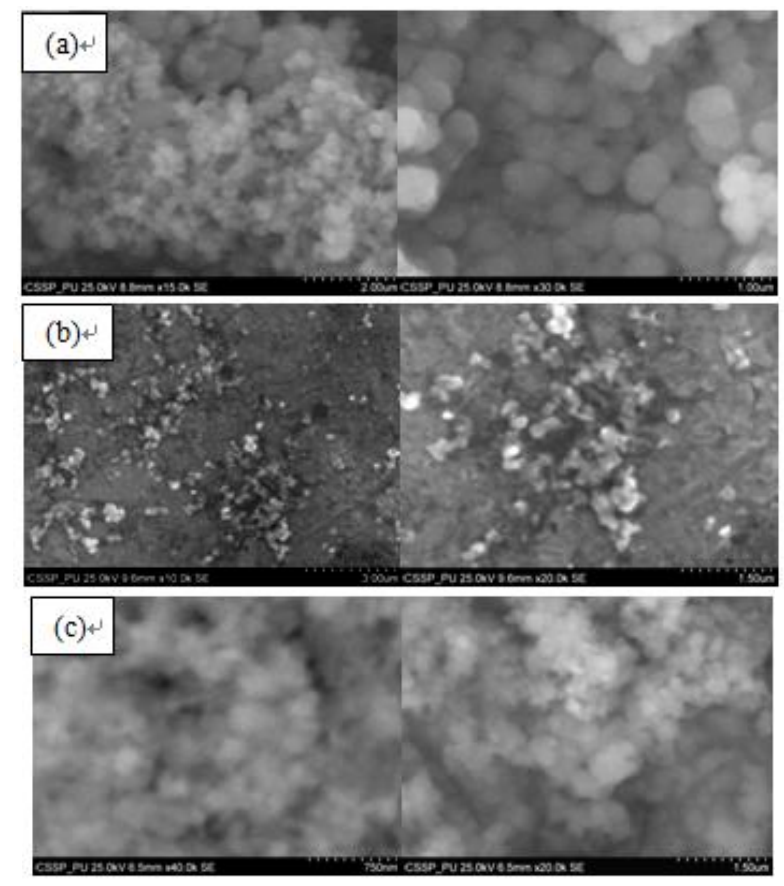

Fig. 3 SEM images of electrodeposited aluminum oxide thin films prepared at 3 volts for reaction time of (a) 30mins, (b) 60mins and (c) $90 \mathrm{mins}$

Surface morphology of electrodeposited aluminum oxide thin films at atomic level was observed by AFM. Figures 4(ac) and Figures 5(a-c) show 3D and 2D AFM images of films prepared at 3 volts for 30,60 and 90 minutes.

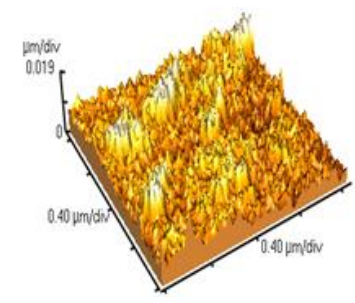

(a)

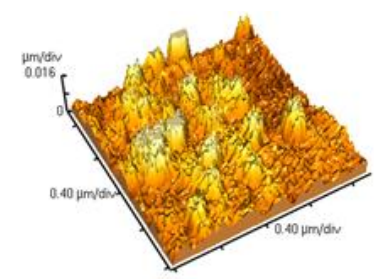

(b)

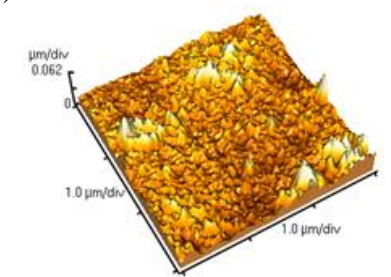

(c)

Fig. 4 3D AFM images at 3 volts for (a) 30, (b) 60 and (c) 90 minutes
Roughness of films increases by increasing the reaction time. Initially, $\mathrm{R}_{\mathrm{rms}}$ was observed to be $5.06 \mathrm{~nm}$
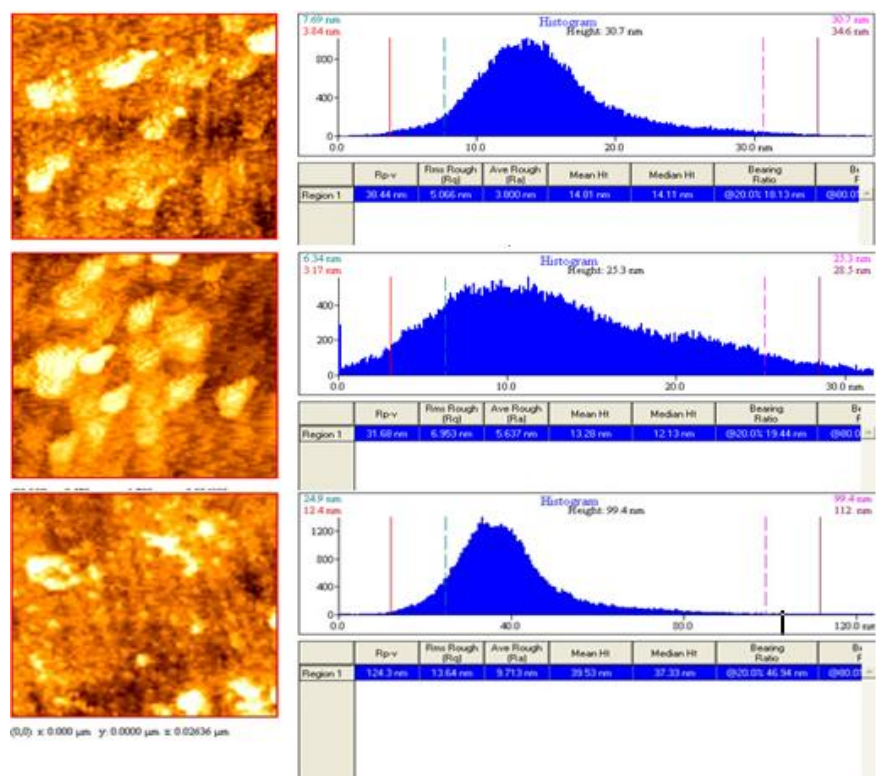

Fig.5 2D AFM images and surface profile at 3 volts for (a) 30, (b) 60 and (c) 90 minutes

which increased to $13.64 \mathrm{~nm}$ when time was increased from 30 to 90 minutes. Moreover, increase in particle size can also be seen in these AFM images [Figures 4 and 5] which is in consistent with SEM results.

\section{Conclusions}

Aluminum oxide films have been of interest in space and aerospace applications as a barrier coating. Electrodeposition method was used for preparation of aluminum oxide thin films at room temperature for applied voltage ranging in between $1-5$ volts. XRD results showed the preferred orientation of the films along (222) plane. SEM images have shown a change in surface morphology for 4 and 5 volts. Detailed study was carried out at 3 volts by varying the reaction time from 15 to 90 minutes. AFM results have shown that reaction time of 15 and 30 minutes are suitable for the preparation of continuous dense coating of aluminum oxide to be used as a barrier layer. Roughness of the films was also increased by increasing the reaction time.

\section{Acknowledgments}

This work was supported by higher education commission (HEC), Pakistan under Grant given to COE in Solid State Physics.

\section{References}

[1] C. Tonon, C. Duvignacq, G. Teyssedre, and M. Dinguirard, J. Phys. D: Appl. Phys. 34, 124 (2001)

[2] K. Fayazbakhsh, and A. Abedian, J. Adv. Spac. Res. 45, 741 (2010)

[3] Y. Goueffeon, G. Aldebert, C. Mabru, L. Arurault, C. Tonon, and P.Guigue, 11th International Symposium on Materials in Space Environment, (2009) August 15-17; Aix-en-Provence, France 
[4] M. Yu, W. Jiang, J. H. Liu, and S. M. Li, J. Adv. Mater. Res. 233, 2166 (2011)

[5] A. K. Sharma, H. Bhojraj, V.K. Kaila, and H. Narayanamurthy, J. Met. Finish. 9514 (1997)

[6] Y. Goueffeon, G. Aldebert, C. Mabru, L. Arurault, C. Tonon, and P.Guigue, J. Mech. Mater. 45, 72 (2011)

[7] C. S. Kumar, S.M. Mayanna, K. N. Mahendra, A. K. Sharma, and R. U. Rani, J. Appl. Surf. Sci. 151, 280 (1999)

[8] Y. Goueffeon, G. Aldebert, C. Mabru, L. Arurault, C. Tonon, and P. Guigue, J. Mater. Process. Technol. 209, 5145 (2009)

[9] W. Qin, B. Cui, X. H. Wu, and Z. H. Jiang, J. Key Eng. Mat. 336, 643 (2007)

[10] X. Y. Sheng, B. F. Klampfl, and E. V. Barrera, J. Scripta Mater. 35, 205 (1996)

[11] S. Joshi, W. G. Fahrenholtz, and M. J. O’Keefe, J. Appl. Surf. Sci. 257, 1859 (2011)

[12] M. Dixit, R. S. Mishra, and K. K. Sankaran.J. Mater. Sci. Eng. A 478, 163 (2008)

[13] E.S. P-Cabrera, C. V. Gutie , I. Irausqu, J. L. Barbera-Sosa, and G. Mesmacque, Int. J. Fatig. 28, 1854 (2006)

[14] S. K. Panigrahi, and R. Jayaganthan, J. All, J. Alloy Compd. 509, 9609 (2011)

[15] A. Ahamed, A. J. Neelay, and K. Shankar, J. Metall. Mater. Transc. A 42A, 795 (2011)

[16] Y. L. Wu, F. H. Froes, C. Li, and A. Alvarez, J. Metall. Mater. Transc. A 30A, 1017 (1999)

[17] M. R. Roknia, A. Z. Hanzakia, and H. R. Abedi, J. Mater. Sci. Eng. A $532,593(2012)$
[18] P. Dasa, R. Jayaganthan, T. Chowdhuryc, and I. V. Singh, J. Mater. Sci. Eng. A 528, 7124 (2011)

[19] M. J. Bartolome, J. F. dal Rio, E. Escudero, S. Feliu Jr, V. Lopez, E. Otero, and J. A. Gonzalez, J. Surf. Coat. Technol. 202, 2783 (2008)

[20] F. Snogan, C. Blance, G. Mankowski, and N. Pebere, J. Surf. Coat. Technol. 154, 94 (2002)

[21] E. Cirik, and K. Genel, J. Surf. Coat. Technol. 202, 5190 (2008)

[22] M. D. Blue, and S. Perkowitz, J. Appl. Opt. 31, 4305 (1992)

[23] M. R. Dury, T. thaeocharous, N. Harrison, N. Fox, and M. Hilton, J. Opt. Commun. 270, 262 (2007)

[24] H. S. Ginell, Nuclear and space radiation effects on materials. USA: National Aeronautics and space administration (1970)

[25] Anon, Handbook of optical properties of thermal control surfaces, Lockheed Missiles \& Space Co. (1967)

[26] H. W. Babel, C. Jones, and K, David, Acta Astro. 39, 369 (1996)

[27] B. Jayaraj, S. Vishawiswaraiah, V. H. Desai, and Y. H. Sohn, J. Surf. Coat. Technol. 177, 140 (2005)

[28] W. Xiaohng, Q. Wei, C. Bo, J. Zhaohua, L. Weiqiang, and H. Weidoung, J. Mater. Process. Technol. 200, 405 (2008)

[29] A. Hakimizad, K. Raeissi, and F. Ashrafizadeh, J. Surf. Coat. Technol. 206, 2438 (2012)

[30] W. Bensalah, M. Feki, M. Wery, and H. F. Ayedi, J. T. Nonferr. Metal Soc. 21, 1773 (2011)

[31] C. S.Kumar, A.K. Sharma, K.N. Mahendra, and S.M. Mayanna, J. Solar Energy Mater. Solar Cells 60, 51 (2000)

[32] S. Riaz, S. Shamaila, B. Khan and S. Naseem, Sur. Rev. Lett., 15, 681 (2008) 